\title{
Governmental Transfers and Altruistic Private Transfers
}

\author{
Amihai Glazer \\ Department of Economics \\ University of California, Irvine \\ Irvine, California 92697 \\ USA \\ Hiroki Kondo \\ Department of Economics \\ Sophia University \\ 7-1 Kioicho Chiyoda-ku Tokyo \\ 102-8554 Japan
}

May 13, 2012

\begin{abstract}
An altruistic agent who may aid a person with a low income may induce that person to exert little effort to increase his income. Such behavior generates a Good Samaritan Dilemma, in which welfare is lower than when no one is altruistic. Governmental transfers, which restrict reallocation from a person who saves much to one who saves little, reduce the effect, and can lead to an outcome which is Pareto-superior to the outcome under a Nash equilibrium with no government taxation and transfers.
\end{abstract}

Keywords: Social security; Moral hazard; Savings; Altruism

JEL classification: D13; D64; D91 


\section{Introduction}

Members of a family are often altruistic to other members. Think of parents caring about their children. Though some family members may be altruistic, others may be selfish. A child may want to get a large transfer from his parents, even if that impoverishes his parents, and even if the transfer comes at the expense of reduced transfers to his brothers and sisters.

Considered below are two potential recipients within a family, with each believing that if he is poorer than the other, then the donor will reallocate transfers from the less poor recipient to the poorer one. Such attitudes of recipients make the donor's generosity a common pool, leading one person, say recipient 1 , to behave in a way that increases the transfers the donor (say parents) makes to recipient 1 , recognizing that the donor will reduce transfers to recipient 2. Some evidence is consistent with this mechanism. ${ }^{1}$

For intuition, suppose the donor will transfer a fixed total amount, say $\$ 10,000$, to the recipients. He will allocate that amount between the two recipients so that in period 2 the marginal utilities of consumption to the recipients are equal. Therefore, for a given transfer, the less recipient 1 saves in period 1 , the higher his marginal utility of consumption in period 2, the less the donor will transfer to recipient 2 , and the more the donor will transfer to recipient 1. Each recipient has an incentive to save little in period 1.

A donor may therefore favor policies which reduce the incentives of the recipients to behave in ways which induce transfers. The donor may benefit by committing to limit his transfer. For example, a parent may tell a child that even if the child saved nothing the parent will give him no more than $\$ 10,000$. The child will then have a marginal incentive to save. But an individual may find it difficult to commit to his future actions.

In contrast, policy set by government can make that commitment. Suppose the donor must pay $\$ 10,000$ in taxes, which government uses to make a transfer payment of $\$ 5,000$ to each of the two recipients. The policy has two effects. First the donor's wealth declines by $\$ 10,000$ and so he will be less willing to make any transfer to either recipient. ${ }^{2}$ Second, the donor cannot take some of the $\$ 5,000$ government transferred to one recipient and give it to the other. Therefore, each recipient has less incentive to reduce his wealth with the aim of increasing the private transfer he gets. So a potential donor may favor a compulsory government transfer program, for example, a social security program that transfers money to his elderly parents and parents-in-law. This benefit of governmental transfers differs from the justifications for social security commonly found in the literature.

\footnotetext{
${ }^{1}$ Parents indeed give greater financial assistance to their children with low incomes than to their children with high incomes (McGarry and Schoeni 1995). A child is more likely to receive a gift from parents if she works fewer hours and has lower income than her brothers and sisters (Hochguertel and Ohlsson 2009).

${ }^{2}$ Robert (1984) shows that public relief programs crowd out private charity in the United States. Cox, Hansen and Jimenez (2004) find that public income redistributive programs substantially crowd out private transfers, especially for lower income households in the Philippines.
} 


\section{Literature}

Consideration of how altruism can lead to a moral hazard problem is examined under the rubric of the Good Samaritan Dilemma (Buchanan 1977). That in turn builds on literature which supposes that donors care about the well-being of the recipients of charity (Hochman and Rodgers 1969, Warr 1982, Roberts 1984).

Altruism and selfishness also appear in the Rotten Kid Theorem: if all potential recipients get transfers from an altruist, then under some (but not all) conditions the potential recipients, even if selfish, gain from maximizing the joint income of donors and recipients (Becker 1974). ${ }^{3}$ But within a family, a Good Samaritan Dilemma can arise, with a child saving little in period 1, so at to induce a large transfer in period 2. As Bruce and Waldman (1990) show, the problem can be ameliorated if the parent commits in period 1 to a minimum transfer in period 2; the same effect can appear with government taxing the parents and making a transfer the child. But this, and related work, does not consider strategic interactions among potential recipients. Our work introduces two recipients, and so does.

Consideration of competition among potential recipients resembles in spirit the idea of the strategic bequest motive - parents offer a larger bequest to a child the more services that child provides the parents, and so the children compete among themselves to give more services (Bernheim, Shleifer, and Summers 1985). The children's strategic interactions lead to the donor's most preferred outcome. In our model, in contrast, their strategic interactions lead to a race to the bottom.

Social security systems have been justified, or explained, on two main grounds. One is paternalism (Diamond 1977). The other justification is to alleviate the Good Samaritan Dilemma described above. Alleviating the Good Samaritan Dilemma does not require a social security program to tax future recipients of the government transfer. Instead, the efficiency gains of the governmental transfer arise from taxing current potential donors who would otherwise, or in addition, make transfers to current recipients (Coate 1995). ${ }^{4}$ Most work, however, ignores the allocation of transfers across recipients.

\footnotetext{
${ }^{3}$ Conditions under which the Rotten Kid Theorem holds are given by Bergstrom (1989): with more than two goods, consumption in two periods, transferable utility, and utility of a recipient a normal good for the donor, the donor's most preferred outcome is realized as a subgame-perfect equilibrium. Utility is transferable if whenever a distribution of utilities is possible, any distribution of utilities in which the sum of the utilities is unchanged is also possible. The utility function must be quasi-linear.

${ }^{4} \mathrm{An}$ overlapping generations model where not altruism but the positive externalities that the young receives from the elderly's consumption induce the young to make transfers to the old is considered by Veall (1986). The transfers in turn induce the old to save less, relying on their children for retirement assistance. Hence a funded public pension plan is subject to crowding out of private transfers. A pay-as-you-go public pension is not subject to crowding out, and is Pareto improving. Homburg (2000) shows that in a model with three goods (current consumption, future consumption, and labor), compulsory savings alleviate the problem of insufficient saving, but reduces labor supply.
} 


\section{Assumptions}

The population consists of identical families, each having one donor and two potential recipients. The donor can be thought of as the parents, and the recipients as their two children. Each recipient is selfish, his utility increasing only with his consumption. A recipient, endowed with wealth $w$ in period 1 , lives for two periods. In period 1 recipient $i(i=1$ or $i=2)$ allocates wealth between consumption and saving. Potential recipient $i$ saves $S_{i}$. In period 2 a recipient's consumption equals his savings, plus a transfer from the donor, plus a transfer from government.

The donor's endowment in period 2 is $w$. His utility increases with his consumption and with the consumption of each recipient. A donor spends his endowment on his consumption, on a transfer to each recipient, and on taxes which finance governmental transfers to the recipients. The donor's transfer to recipient $i$ is called $d_{i}$. In period 2 the donor pays a tax of $T$, government transfers $t_{i}$ to recipient $i$, with $t_{1}+t_{2}=T$. The analysis will emphasize symmetric behavior, where $t_{1}=t_{2}=T / 2$, but will also show that similar results hold when only one person gets a governmental transfer. Thus, in period 2 recipient $i$ consumes $S_{i}+d_{i}+t_{i} \cdot{ }^{5}$

The timeline follows:

1. Government determines the tax the donor will pay in period 2, and the governmental transfers in period 2

2. Each recipient saves some of his endowment

3. Government makes transfers to recipients

4. A donor makes transfers to recipients in his family

5. Utilities are realized

A recipient's utility from consumption in the two periods is

$$
\ln \left(w-S_{i}\right)+\beta \ln \left(S_{i}+d_{i}+\frac{T}{2}\right), \quad i=1,2,
$$

where $\beta$ is a parameter indicating the weight on consumption in period 2 .

In period 2 a donor consumes $w-d_{1}-d_{2}-T$; his utility from such consumption is $\ln \left(w-d_{1}-d_{2}-T\right)$. A donor's utility also increases with the utility of each recipient:

$$
\begin{aligned}
\ln \left(w-d_{1}-d_{2}-T\right) & +\alpha\left[\ln \left(w-S_{1}\right)+\beta \ln \left(S_{1}+d_{1}+\frac{T}{2}\right)\right] \\
& +\alpha\left[\ln \left(w-S_{2}\right)+\beta \ln \left(S_{2}+d_{2}+\frac{T}{2}\right)\right],
\end{aligned}
$$

\footnotetext{
${ }^{5}$ We can think of $N$ identical families, each consisting of a donor and of two recipients. The government's total tax revenue is $N T$, which it distributes among $2 N$ recipients in the population.
} 
where $\alpha$ is the weight a donor places on the utilities of recipients in his family.

The governmental transfer $T$ is determined, for example, by voting. No one person's vote is decisive, so that no individual donor or recipient can alter government policy: a donor must pay $T$, even if he alone wants to pay more or less than that. A donor can increase consumption of a recipient in his family by making private transfers. A recipient can affect the transfer he gets from the donor in his family by choosing how much to save.

\section{Transfers and savings with no commitment}

A donor cannot commit to the amount he will transfer, nor can he make a transfer before potential recipients set savings. The limitations may arise because the donor may not have the money to make a transfer so early, or because each recipient has an incentive to spend money soon, before the donor makes his transfer. Thus, let recipients simultaneously choose their savings, $S_{1}$ and $S_{2}$. After that, a donor makes private transfers, $d_{1}$ and $d_{2}$ to maximize his objective function (2). His decision is influenced by the choices of $S_{1}$ and $S_{2}$. Hence, recipients will choose $S_{1}$ and $S_{2}$ taking into account the donor's behavior.

Therefore, to analyze this game, we first consider the donor's problem; after that we analyze the recipient's choice.

\subsection{Donor's choice of private transfer}

A donor maximizes the objective function (2) with respect to $d_{1}$ and $d_{2}$, subject to the constraints $d_{1} \geq 0$ and $d_{2} \geq 0$. The donor's private transfers $d_{1}$ and $d_{2}$

depend on the recipients' savings $S_{1}$ and $S_{2}$, and on the governmental transfer $T$.

If both $S_{1}$ and $S_{2}$ are sufficiently small to satisfy

$$
S_{i} \leq\left(\frac{\alpha \beta}{1+\alpha \beta}\right) w+\left(\frac{\alpha \beta}{1+\alpha \beta}\right) S_{j}-\frac{1}{2}\left(\frac{1+2 \alpha \beta}{1+\alpha \beta}\right) T, \quad i, j=1,2, \quad i \neq j
$$

then

$$
d_{i}=\frac{\alpha \beta w+\alpha \beta S_{j}-(1+\alpha \beta) S_{i}}{1+2 \alpha \beta}-\frac{1}{2} T \geq 0, \quad i, j=1,2, \quad i \neq j .
$$

If $S_{i}$ is too large to satisfy (3) yet $S_{j}$ is sufficiently small to satisfy

$$
S_{j} \leq \alpha \beta w-\frac{1}{2}(1+2 \alpha \beta) T,
$$

then

$$
d_{i}=0,
$$

and

$$
d_{j}=\frac{\alpha \beta w-S_{j}-\left(\frac{1}{2}+\alpha \beta\right) T}{1+\alpha \beta} \geq 0 .
$$


Lastly, if both $S_{1}$ and $S_{2}$ are too large to satisfy (5), then $d_{1}=d_{2}=0$. See Appendix 1 for the derivations. Figure 1 shows, for a numerical example, combinations of $\left(S_{1}, S_{2}\right)$ satisfying each of the cases.

The private transfer from a donor to recipient $i, d\left(S_{i}, S_{j}, T\right)$, is a function of the amount he saves, $S_{i}$, the amount the other recipient saves, $S_{j}$, and the governmental transfer $T$.

A person who gets no transfer has his utility in period 2 increase with his saving in period 1. A donor therefore benefits more from making a transfer the less the recipient saved. As will be seen below, if commitment for the private transfer is impossible, a recipient has an incentive to save little and to rely on a private transfer from the donor.

\subsection{Savings by recipients}

A recipient expects to get more from the donor the less the recipient saves. He also knows that the recipient who saves less than the other will get a larger transfer from the donor. Specifically, recipient $i$ chooses $S_{i}$ to maximize $\ln (w-$ $\left.S_{i}\right)+\beta \ln \left(S_{i}+d_{1}+\frac{T}{2}\right)$, recognizing that $d_{i}$ is a function of $S_{1}$ and of $S_{2}$.

Figures 2, 3, and 4 show recipient 1's utility (1). Also shown is recipient 1's best response, $S_{1}$, to recipient 2's choice of $S_{2}$.

Recipient 1's best response can take three forms. From (3) and (5), the interval of $\left(S_{1}, S_{2}\right)$ in which recipient 1 saves so much that he gets no private transfer is

$S_{1} \geq \operatorname{Min}\left[\left(\frac{\alpha \beta}{1+\alpha \beta}\right) w+\left(\frac{\alpha \beta}{1+\alpha \beta}\right) S_{2}-\frac{1}{2}\left(\frac{1+2 \alpha \beta}{1+\alpha \beta}\right) T, \alpha \beta w-\frac{1}{2}(1+2 \alpha \beta) T\right]$.

Recipient 1's optimal, or utility-maximizing, saving limited to this interval is

$$
\frac{\beta w-\frac{1}{2} T}{1+\beta} \text {. }
$$

If the amount recipient 1 saves violates (8), he will get a private transfer. If recipient 2 saves little, recipient 1's optimal saving in this interval is

$$
\left(\frac{\beta-1}{1+\beta}\right) w-\left(\frac{1}{1+\beta}\right) S_{2}
$$

In contrast, if recipient 2 saves much, recipient 1 saves

$$
\frac{(\beta-1) w+\frac{1}{2} T}{1+\beta} \text {. }
$$

Appendix 2 gives details about recipient 1's savings and the derivations.

Recipient 1 chooses between (9), (10) and (11), to give him the highest utility. An increase in $S_{2}$ induces recipient 1 to save less, and to rely on a private transfer from the donor, as seen in Figures 2, 3, and $4 .{ }^{6}$ An increase in

\footnotetext{
${ }^{6}$ In some cases, as in Figure 2, recipient 1 may save so much as to induce the donor to make no private transfers.
} 
$S_{2}$ reduces the donor's gain from making a transfer to recipient 2 , and increases the donor's incentive to make a transfer to recipient 1 . Therefore, the donor transfers more to recipient 1 when recipient 1 chooses (10) or (11), making that choice more attractive to recipient 1 . In contrast, if recipient 2 saves little, recipient 1 will get only a small transfer from the donor, even if the recipient chooses (10) or (11). Recipient 1 will then avoid saving little.

\subsection{Private transfers and savings in equilibrium}

The game between the two recipients can have three different equilibria. An important equilibrium has each recipient save little, so that the donor makes a private transfer to each. Figure 3 depicts an example in which this outcome is a Nash equilibrium. From (10), savings in this equilibrium are

$$
S_{i}=\left(\frac{\beta-1}{2+\beta}\right) w, \quad i=1,2 .
$$

From (4) and (12), private transfers are:

$$
d_{i}=\left[\frac{1-\beta+\alpha \beta^{2}+2 \alpha \beta}{(1+2 \alpha \beta)(2+\beta)}\right] w-\frac{1}{2} T, \quad i=1,2,
$$

and from (1), the corresponding maximized utilities are

$$
\ln \left(\frac{3}{2+\beta}\right) w+\beta \ln \left[\frac{3 \alpha \beta^{2}}{(1+2 \alpha \beta)(2+\beta)}\right] w .
$$

To consider the conditions under which (12) is a Nash equilibrium, we examine whether recipient 1 gains by saving an amount different from (12), given that recipient 2 chooses (12).

Suppose recipient 1 saves a bit more than (12), thereby improving the intertemporal allocation of his consumption. The increased saving reduces the donor's benefit from making a transfer. The reduced transfer dominates the improved intertemporal allocation, so that recipient 1's utility declines.

When, however, recipient 1 saves more than some critical value, the donor reduces his transfer to zero. Further increased saving by recipient 1 does not further reduce the private transfer, so that increased saving improves intertemporal allocation of consumption, and so benefits the recipient. Consider the interval $\left(S_{1}, S_{2}\right)$ where $S_{2}=\left(\frac{\beta-1}{2+\beta}\right) w$ yet $S_{1}$ is too large to satisfy (3) (with $i=1$ and $j=2$ ). The amount recipient 1 saves in this interval is $\frac{\beta w-\frac{1}{2} T}{1+\beta}$, and his utility is

$$
\ln \left(\frac{1}{1+\beta}\right)\left(w+\frac{1}{2} T\right)+\beta \ln \left(\frac{\beta}{1+\beta}\right)\left(w+\frac{1}{2} T\right) .
$$

If, however, the maximized utility with no private transfer (15) is less than the maximized utility with a private transfer (14), recipient 1 does not deviate 
from (12). In the Nash equilibrium a person's savings are given by (12) and the private transfers are given by (13).

If the governmental transfer is zero, whether (14) exceeds (15), and whether in a Nash equilibrium each recipient saves the amount given by (12), depends on the weight the donor places on the recipient's utility $(\alpha)$, and on how much recipients value consumption in period $2(\beta)$.

\section{Proposition 1}

Let $\alpha$ be the weight the donor places on a recipient's utility, and $\beta$ the intertemporal discount factor. If $\alpha$ is sufficiently large and $\beta$ is sufficiently small, then

in the Nash equilibrium each recipient saves $\left(\frac{\beta-1}{2+\beta}\right) w$ and each gets a private transfer.

Proof See Appendix 3.

In Figure 5, area I corresponds to the set of $(\alpha, \beta)$ indicated by Proposition 1. Equations which describe the set of $(\alpha, \beta)$ are complicated, as shown in Appendix 3.

Large $\alpha$ means that the donor is eager to make a private transfer. Hence, for a wider range of other parameters will the recipient enjoy higher utility by saving little, and getting a private transfer. In the following we shall make use of the notation $\bar{d}$ denoting the private transfer from the donor to a recipient for the case discussed in Proposition 1, where $T=0$ and $\alpha$ is large. This $\bar{d}$ equals (13) in which $T=0$.

\section{Governmental transfer}

Under some conditions, a governmental transfer, which encourages recipients to save, can be efficient. We consider first a governmental transfer to both recipients, showing that such a transfer can benefit both recipients, and also benefit the donor. We then consider a governmental transfer to only one recipient, finding similar results.

\subsection{Governmental transfers to both recipients}

The main point of this paper appears in the following proposition, which claims that a policy which taxes the donor and uses that revenue to make unconditional transfers to recipients can benefit the donor and both recipients.

\section{Proposition 2}

Let $\bar{d}$ be the equilibrium private transfer from the donor to each recipient when government makes no transfer. There exists a positive governmental transfer smaller than $2 \bar{d}$ which generates a Nash equilibrium in which each recipient saves $\frac{\beta w-\frac{1}{2} T}{1+\beta}$ and the donor makes no private transfer. The donor and both recipients are better off than in the equilibrium with no governmental transfer. 
Proof See Appendix 4.

To understand this effect, suppose government taxes the donor, and makes a transfer to each recipient, equal to the amount of the private transfer that a recipient gets in the equilibrium when government makes no transfer. That is, $T=2 \bar{d}$.

As discussed above, the larger the governmental transfer, the smaller the donor's benefit from making a private transfer. Therefore, even a recipient who saves little, in the amount $\left(\frac{\beta-1}{2+\beta}\right) w$, gets no private transfer. The amount the recipient gets is the same as when government made no transfer. Hence, the recipient's utility is also the same as it was, (14).

A recipient can enjoy higher utility by saving more than $\left(\frac{\beta-1}{2+\beta}\right) w$. Increased saving by a recipient does not further reduce the private transfer, so that increased saving improves the intertemporal allocation of consumption and increases the recipient's utility.

Therefore, the recipient's utility (15) when he saves $\frac{\beta w-\frac{1}{2} T}{1+\beta}$ is strictly greater than his utility when he saves only $\left(\frac{\beta-1}{2+\beta}\right) w$. Even when $T$ is somewhat smaller than $2 \bar{d}$, the recipient gains by increasing his saving. Therefore, when $0<T<$ $2 \bar{d}$, it is a stable Nash equilibrium for each recipient to save $\frac{\beta w-\frac{1}{2} T}{1+\beta}$.

Such a governmental transfer benefits the donor and the recipients. The recipient's utility in the new Nash equilibrium is (15), which is higher than in the equilibrium with no governmental transfer (14). Also, the donor's utility from his consumption is higher: in the new equilibrium, $T<2 \bar{d}$, and $d_{1}+d_{2}=0$; his total payments in the new Nash equilibrium, $T$ plus private transfer $d_{1}+d_{2}$, are smaller than transfers in the initial equilibrium, $2 \bar{d}$.

Conversely, a Nash equilibrium with no governmental transfer is inefficient. As shown in Proposition 1, Pareto inefficiency tends to occur when the donor makes large private transfers. Recipients depend on the private transfers from the donor, and the competition between the two recipients to attract private transfers makes matters worse.

A governmental transfer, however, may fail to increase welfare. One situation has a governmental transfer crowd out a private transfer. An increase in the governmental transfer impoverishes the donor and enriches the recipients, thereby reducing the donor's gain from private transfers to recipients. If the recipients' savings, $S_{1}$ and $S_{2}$, are sufficiently small to satisfy (3), the donor will make a positive transfer to each recipient, yet the donor will reduce private transfers $d_{1}$ and $d_{2}$ to offset the increased governmental transfer, as can be seen in (4). Therefore, the sum of private and governmental transfers to recipient $i$, $d_{i}+T / 2$, is unchanged, and an increase in the governmental transfer leaves each recipient's utility (1) unchanged. $^{7}$ Hence, if recipient $j$ chooses $\left(\frac{\beta-1}{2+\beta}\right) w$ as in (12), the utility-maximizing choice for recipient $i$ in the range of $S_{i}$ in (3), that

\footnotetext{
${ }^{7}$ We can check this by substituting $d_{i}$ in (1) using (4).
} 
is, when the recipient gets a private transfer, is also $\left(\frac{\beta-1}{2+\beta}\right) w$, and his utility is (14). This utility is independent of $T$.

A different situation has a recipient get no private transfer, and so gain from an increase in the governmental transfer. Suppose recipient $i$ saves so much that the donor makes no private transfer to the recipient $\left(d_{i}=0\right)$. An increase in the governmental transfer increases recipient $i$ 's utility (1), as the sum of private and governmental transfers to him, $d_{i}+T / 2=0+T / 2$, increases. Therefore, recipient $i$ 's utility when he gets no private transfer (15) also increases. ${ }^{8}$

To summarize, an increase in the governmental transfer can induce a recipient to save more. Put differently, when the governmental transfer is large, the total transfer (the sum of private and governmental transfers) to a recipient is less sensitive to a change in his savings. To see this effect, recall that the private transfer $d\left(S_{i}, S_{j}, T\right)$ declines with the recipient's savings, whereas the governmental transfer is independent of savings. When the governmental transfer is large, the sensitive private transfer is very small, and so changes in the total transfer will not induce recipients to save less.

\subsection{Governmental transfer to only one recipient}

One might think that governmental transfers are efficient only because an individual realizes that when he saves more he will not reduce the governmental transfer to him, so that he has greater incentive to save. But an important added effect appears - a donor can reallocate his private transfer from one recipient to another, but cannot reallocate a governmental transfer. The effect is highlighted by considering a governmental transfer to only one of the two recipients in each family, and show how it affects the behavior of both recipients. Though we speak of a governmental transfer which the donor cannot reallocate, similar results apply if only one recipient has the right to receive a transfer, as under the law or custom of primogeniture.

Let the governmental transfer to recipient 2 be $T$. Recipient 1 gets no governmental transfer. For mnemonic purposes, call the recipient who gets a governmental transfer recipient $R_{G}$; call the recipient who gets no governmental transfer recipient $R_{N G}$.

Recipient $R_{N G}$ 's best response can take one of three forms, which differ from those derived in section (4). If recipient $R_{N G}$ gets no private transfer, he saves

$$
\frac{\beta w}{1+\beta}
$$

A recipient who saves little will get a private transfer. If recipient $R_{G}$ saves little, the amount recipient $R_{N G}$ saves, given that he gets a private transfer, is

\footnotetext{
${ }^{8}$ If saving by recipient $i$ is too large to satisfy (3) or $(5)$, then $d_{i}=d\left(S_{i}, S_{j}, T\right)=0$, as shown in section (4.1) and Appendix 1. We can check that if $d_{i}=0$, recipient $i$ 's utility (1) increases with $T$. The saving which maximizes (1) when $d_{i}=0$ is $S_{i}=\frac{\beta w-\frac{1}{2} T}{1+\beta}$, which declines with $T$. Recipient $i$ gets a governmental transfer in period 2 . Therefore, as $T$ increases he will smooth out his intertemporal consumption path by saving less in period 1 .
} 
the same as (10). In contrast, if recipient $R_{G}$ saves much, the amount recipient $R_{N G}$ saves, given that he gets a private transfer, is

$$
\frac{(\beta-1) w+T}{1+\beta} \text {. }
$$

So Recipient $R_{N G}$ chooses between the values of expressions (16), (16), and (17); call the amount he saves $S_{N G}$.

Recipient $R_{G}$ 's best response differs from recipient $R_{N G}$ 's best response. If recipient $R_{G}$ gets no private transfer, he saves

$$
\frac{\beta w-T}{1+\beta} \text {. }
$$

If recipient $R_{N G}$ saves little, the amount recipient $R_{G}$ saves, given that he gets a private transfer, is

$$
\left(\frac{\beta-1}{1+\beta}\right) w-\left(\frac{1}{1+\beta}\right) S_{N G} .
$$

If recipient $R_{N G}$ saves much, the amount recipient $R_{G}$ saves, given that he gets a private transfer, is

$$
\left(\frac{\beta-1}{1+\beta}\right) w
$$

Appendix 2 gives detailed derivations. Each recipient will choose between the different levels of savings to give him the highest utility.

Suppose the weight $(\alpha)$ the donor places on a recipient's utility is large, and that the intertemporal discount factor $(\beta)$ is small. As Proposition 1 indicates, if government makes no transfer, in the Nash equilibrium recipients save little, in the amount $\left(\frac{\beta-1}{2+\beta}\right) w$, and rely on a private transfer $\bar{d}$ from the donor. Now suppose that government taxes the donor, and makes a transfer to recipient $R_{G}$, equal to the amount that a recipient gets in the equilibrium when government makes no transfer. That is, $T=\bar{d}$. Figure 6 shows recipients' utilities (1) and the recipients' best responses under such a governmental transfer.

If both recipients save little, in the amount $\left(\frac{\beta-1}{2+\beta}\right) w$, each recipient's utility is the same as when government made no transfer. Recipient $R_{N G}$ gets a private transfer of $d_{N G}=\bar{d}$ that is the same as he would get were government to make no transfer. Recipient $R_{G}$ gets a governmental transfer $T=\bar{d}$, but gets no private transfer, or $d_{G}=0$. Thus, recipient $R_{G}$ gets the same total transfer as when government made no transfer.

Recipient $R_{G}$, however, can gain by saving more than $\left(\frac{\beta-1}{2+\beta}\right) w$. When government made no transfer, if he saved more than $\left(\frac{\beta-1}{2+\beta}\right) w$, the donor reduced the transfer to him, making it less than $\bar{d}$. Now, however, recipient $R_{G}$ gets $\bar{d}$ not from the donor but from the government. An increase in the amount recipient $R_{G}$ saves does not reduce the governmental transfer, but improves his intertemporal consumption allocation. Therefore, recipient $R_{G}$ increases his savings to $\frac{\beta w-T}{1+\beta}$. 
Recipient $R_{N G}$ will also save more, though less than recipient $R_{G}$. With the governmental transfer to recipient $R_{G}$, recipient $R_{N G}$ will save $\frac{(\beta-1) w+T}{1+\beta}$. An increase in the amount $R_{N G}$ saves reduces the private transfer from the donor. The private transfer, however, is less sensitive to a change in recipient $R_{N G}$ 's savings than when government makes no transfer to recipient $R_{G}$. When government makes no transfer and one recipient saves little, increased saving by the other recipient induces the donor to reduce the transfer to the high-saver and increase the transfer to the low-saver. When, however, government makes a transfer only to recipient $R_{G}$, and recipient $R_{G}$ saves much, recipient $R_{G}$ becomes richer. An increase in the amount recipient $R_{N G}$ saves still induces the donor to reduce his transfer to recipient $R_{N G}$, but the reduction is smaller than when government made no transfer. The less sensitive change in a private transfer makes the recipient less eager to rely on it.

Thus, a governmental transfer to only one recipient benefits both recipients. The donor's total payments, $T=\bar{d}$ plus the private transfer to recipient $R_{N G}$, which is smaller than $\bar{d}$, are smaller than total payments in the initial equilibrium $2 \bar{d}$. Therefore, the governmental transfer also benefits the donor. In short, the government transfer yields a Pareto-superior outcome.

\section{Conclusion}

A potential recipient recognizes that if he is more needy than other recipients, the donor will give him a larger transfer. Such behavior can lead to a race to the bottom, in which each recipient has an incentive to make himself more needy. Some governmental policies can mitigate the problem. In particular, transfers by government which are not under the control of the donor, and which are insensitive to the needs of recipients, can eliminate the race to the bottom. The governmental transfer has two effects on the behavior of the recipients. First, if the governmental transfer made to any one person is unaffected by his behavior (as largely holds for social security) then the recipient gains more from increasing his saving. Second, because the governmental transfer is not reallocated as a recipient saves more, a person who gets no governmental transfer will also save more - recipient 2 will save more if recipient 1 gets a governmental transfer. So the purpose of governmental assistance is not only to benefit the recipient, but also to address the moral hazard problem arising with people not given governmental assistance.

Though we spoke of social security and of savings, the line of reasoning can apply to other areas. Thus, a similar analysis can apply when a potential recipient can choose effort which determines his income. And the mechanism we highlight need not be the only one in operation. It can make a difference only at the margin, or explain why donors acquiesce to governmental taxes and spending. 


\section{Appendix 1: Donor's choice of private transfer}

The values of $d_{1}$ and $d_{2}$ that maximize (2) satisfy

$$
\begin{gathered}
\frac{-1}{w-d_{1}-d_{2}-T}+\frac{\alpha \beta}{S_{1}+d_{1}+t_{1}} \leq 0, \\
d_{1} \geq 0, \\
\left(\frac{-1}{w-d_{1}-d_{2}-T}+\frac{\alpha \beta}{S_{1}+d_{1}+t_{1}}\right) d_{1}=0, \\
\frac{-1}{w-d_{1}-d_{2}-T}+\frac{\alpha \beta}{S_{2}+d_{2}+t_{2}} \leq 0, \\
d_{2} \geq 0
\end{gathered}
$$

and

$$
\left(\frac{-1}{w-d_{1}-d_{2}-T}+\frac{\alpha \beta}{S_{2}+d_{2}+t_{2}}\right) d_{2}=0
$$

where $t_{i}$ is the governmental transfer to recipient $i$, and $t_{1}+t_{2}=T$.

If both $d_{1}$ and $d_{2}$ are positive, from (23) and (26) we can see that both (21) and (24) hold as an equality. Solving them for $d_{1}$ and $d_{2}$ yields

$d_{i}=\left(\frac{\alpha \beta}{1+2 \alpha \beta}\right)\left(w-T+S_{j}+t_{j}\right)-\left(\frac{1+\alpha \beta}{1+2 \alpha \beta}\right)\left(S_{i}+t_{i}\right) \geq 0, \quad i, j=1,2, \quad i \neq j$.

From (27), the conditions under which $d_{1}$ and $d_{2}$ are positive are

$$
S_{i} \leq\left(\frac{\alpha \beta}{1+\alpha \beta}\right)\left(w-T+S_{j}+t_{j}\right)-t_{i}, \quad i, j=1,2, \quad i \neq j .
$$

When $t_{1}=t_{2}=\frac{1}{2} T$, expression (27) becomes (4), and (28) becomes (3).

If $d_{2}$ is positive yet $d_{1}=0$, inspection of (26) shows that (24) hold as an equality. Solving $(24)$ as an equality and $d_{1}=0$ yields

$$
d_{2}=\left(\frac{\alpha \beta}{1+\alpha \beta}\right)(w-T)-\left(\frac{1}{1+\alpha \beta}\right)\left(S_{2}+t_{2}\right) \geq 0 .
$$

Expression (29) is positive if

$$
S_{2} \leq \alpha \beta(w-T)-t_{2}
$$

Substituting $d_{2}$ and $d_{1}$ in (21) using (29) and $d_{1}=0$ and rearranging yields the condition under which $d_{1}=0$. This condition is the inverse of the condition (28) (with $i=1$ and $j=2$ ). When $t_{1}=t_{2}=\frac{1}{2} T$, (29) is written as (7) (with $j=2$ ), and (30) is written as (5) (with $j=2$ ).

Lastly, if $d_{1}=0$ and $d_{2}=0$, from (23) and (26), we can see that (21) and (24) hold. Rearranging them yields

$$
S_{i} \geq \alpha \beta(w-T)-t_{i}, \quad i=1,2 .
$$




\section{Appendix 2: Recipient 1's savings as a function of recipient 2's savings}

From $(28)$ and $(31)$, the interval of $\left(S_{1}, S_{2}\right)$ in which recipient 1 gets no transfer is

$$
S_{1} \geq \operatorname{Min}\left[\left(\frac{\alpha \beta}{1+\alpha \beta}\right)\left(w-T+S_{2}+t_{2}\right)-t_{1}, \alpha \beta(w-T)-t_{1}\right] .
$$

When $t_{1}=t_{2}=\frac{1}{2} T,(32)$ is written as (8).

\section{Appendix 2.1: Recipient 1's optimal savings limited to the interval (32)}

Differentiating (1) with respect to $S_{1}$ with $d_{1}=0$ yields:

$$
\frac{-1}{w-S_{1}}+\beta\left(\frac{1}{S_{1}+t_{1}}\right) \text {. }
$$

If $S_{1}$ in the interval (32) makes (33) zero, this $S_{1}$ is recipient 1's optimal savings in this interval. From (33), this $S_{1}$ is

$$
S_{1}=\frac{\beta w-t_{1}}{1+\beta} .
$$

When $t_{1}=\frac{1}{2} T$, this expression becomes (9). When $t_{1}=0$ and $t_{2}=T,(34)$ becomes (16), and (34) for recipient 2 becomes (18). This value minus $\alpha \beta(w-$ $T)-t_{1}$ yields

$$
\frac{\beta(1-\alpha(1+\beta)) w+\beta\left(t_{1}+\alpha(1+\beta) T\right)}{1+\beta} .
$$

As $0<\beta<1$ and $0<\alpha<1 / 2$, this expression is positive. Savings $\frac{\beta w-t_{1}}{1+\beta}$ are higher than the border of (32) and thus it is the optimal choice.

\section{Appendix 2.2: Recipient 1's optimal savings limited to the interval of $S_{1}$ too small to satisfy (32)}

The interval in which $S_{1}$ is smaller than the right side of (32) is divided into two intervals. In one of the intervals, $S_{1}$ is smaller than the border of (28) (with $i=1$ and $j=2$ ), but larger than the border of (28) (with $i=2$ and $j=1$ ), so that the donor makes positive transfers to both recipients 1 and 2 , as in (27). That is,

$S_{1} \in\left[-\left(w-T+t_{1}\right)+\left(\frac{1+\alpha \beta}{\alpha \beta}\right)\left(S_{2}+t_{2}\right),\left(\frac{\alpha \beta}{1+\alpha \beta}\right)\left(w-T+S_{2}+t_{2}\right)-t_{1}\right]$. 
In the other interval, $S_{1}$ is smaller than the border of (28) (with $i=2$ and $j=1$ ) and the border of (31) (with $i=1$ ). When $\left(S_{1}, S_{2}\right)$ lies in this interval, the donor makes a transfer only to recipient 1 . This interval is

$$
S_{1} \leq \operatorname{Min}\left[-\left(w-T+t_{1}\right)+\left(\frac{1+\alpha \beta}{\alpha \beta}\right)\left(S_{2}+t_{2}\right), \alpha \beta(w-T)-t_{1}\right] .
$$

We first consider recipient 1's utility-maximizing savings limited to the interval (36). Differentiating (1) with respect to $S_{1}$, with $d_{1}$ that is equal to (27), yields

$$
\frac{-1}{w-S_{1}}+\beta\left(\frac{1}{S_{1}+d\left(S_{1}, S_{2}, T\right)+t_{1}}\right)\left[1-\left(\frac{1+\alpha \beta}{1+2 \alpha \beta}\right)\right] .
$$

If $S_{1}$ in the interval (36) makes (38) zero, this $S_{1}$ is recipient 1's optimal savings in this interval. From (38) and (27) (with $i=1$ ), this $S_{1}$ is calculated as (10). If (10) is larger than the upper limit in the interval (36), recipient 1's optimal $S_{1}$ limited to this interval is the upper limit of this interval. The value of (10) exceeds the upper limit if

$S_{2} \leq\left(\frac{\beta-1-2 \alpha \beta}{1+2 \alpha \beta+\alpha \beta^{2}}\right) w+\left[\frac{\alpha \beta(1+\beta)}{1+2 \alpha \beta+\alpha \beta^{2}}\right]\left(T-t_{2}\right)+\left[\frac{(1+\alpha \beta)(1+\beta)}{1+2 \alpha \beta+\alpha \beta^{2}}\right] t_{1}$.

In contrast, if (10) is smaller than the lower limit in the interval (36), recipient 1's optimal $S_{1}$ in this interval is the lower limit of this interval. The value of (10) is lower than the lower limit if

$S_{2} \geq\left(\frac{2 \alpha \beta^{2}}{1+\beta+2 \alpha \beta+\alpha \beta^{2}}\right) w-\left[\frac{\alpha \beta(1+\beta)}{1+\beta+2 \alpha \beta+\alpha \beta^{2}}\right]\left(T-t_{1}\right)-\left[\frac{(1+\beta)(1+\alpha \beta)}{1+\beta+2 \alpha \beta+\alpha \beta^{2}}\right] t_{2}$.

Consider next recipient 1's optimal savings limited to the interval (37). Differentiating (1) with respect to $S_{1}$ when $d_{1}$ equals the value of (29) for recipient 1 yields

$$
\frac{-1}{w-S_{1}}+\beta\left(\frac{1}{S_{1}+d\left(S_{1}, S_{2}, T\right)+t_{1}}\right)\left[1-\left(\frac{1}{1+\alpha \beta}\right)\right] .
$$

If $S_{1}$ in the interval (37) makes the value of (41) zero, this $S_{1}$ is recipient 1's optimal savings in this interval. From (41) and (29) for recipient 1, this $S_{1}$ is

$$
S_{1}=\frac{(\beta-1) w+T-t_{1}}{1+\beta} .
$$

If (42) exceeds $\alpha \beta(w-T)-t_{1}$, that is, if:

$$
\frac{(\beta-1) w+T-t_{1}}{1+\beta} \geq \alpha \beta(w-T)-t_{1},
$$

then recipient 1's optimal savings limited to this interval is the upper limit of this interval. If (42) is smaller than $\alpha \beta(w-T)-t_{1}$ but greater than $-(w-T+$ 
$\left.t_{1}\right)+\left(\frac{1+\alpha \beta}{\alpha \beta}\right)\left(S_{2}+t_{2}\right)$, the last value is recipient 1's optimal savings limited to this interval. The value of $(42)$ exceeds $-\left(w-T+t_{1}\right)+\left(\frac{1+\alpha \beta}{\alpha \beta}\right)\left(S_{2}+t_{2}\right)$ if:

$$
S_{2} \leq\left[\frac{2 \alpha \beta^{2}}{(1+\alpha \beta)(1+\beta)}\right] w-\left[\frac{\alpha \beta^{2}}{(1+\alpha \beta)(1+\beta)}\right]\left(T-t_{1}\right)-t_{2} .
$$

The right-hand side of (40) is necessarily larger than the right-hand side of (39), and the right-hand side of (44) is necessarily larger than the right-hand side of (40). Therefore, to summarize, recipient 1's optimal savings limited to the interval of $S_{1}$ too small to satisfy (32) are:

if $S_{2} \leq\left(\frac{\beta-1-2 \alpha \beta}{1+2 \alpha \beta+\alpha \beta^{2}}\right) w+\left[\frac{\alpha \beta(1+\beta)}{1+2 \alpha \beta+\alpha \beta^{2}}\right]\left(T-t_{2}\right)+\left[\frac{(1+\alpha \beta)(1+\beta)}{1+2 \alpha \beta+\alpha \beta^{2}}\right] t_{1}$,

$$
S_{1}=\left(\frac{\alpha \beta}{1+\alpha \beta}\right)\left(w-T+S_{2}+t_{2}\right)-t_{1},
$$

if $\left(\frac{\beta-1-2 \alpha \beta}{1+2 \alpha \beta+\alpha \beta^{2}}\right) w+\left[\frac{\alpha \beta(1+\beta)}{1+2 \alpha \beta+\alpha \beta^{2}}\right]\left(T-t_{2}\right)+\left[\frac{(1+\alpha \beta)(1+\beta)}{1+2 \alpha \beta+\alpha \beta^{2}}\right] t_{1} \leq S_{2} \leq\left(\frac{2 \alpha \beta^{2}}{1+\beta+2 \alpha \beta+\alpha \beta^{2}}\right) w-$ $\left[\frac{\alpha \beta(1+\beta)}{1+\beta+2 \alpha \beta+\alpha \beta^{2}}\right]\left(T-t_{1}\right)-\left[\frac{(1+\beta)(1+\alpha \beta)}{1+\beta+2 \alpha \beta+\alpha \beta^{2}}\right] t_{2}, S_{1}$ is $(10)$,

if (43) holds and if $\left(\frac{2 \alpha \beta^{2}}{1+\beta+2 \alpha \beta+\alpha \beta^{2}}\right) w-\left[\frac{\alpha \beta(1+\beta)}{1+\beta+2 \alpha \beta+\alpha \beta^{2}}\right]\left(T-t_{1}\right)-\left[\frac{(1+\beta)(1+\alpha \beta)}{1+\beta+2 \alpha \beta+\alpha \beta^{2}}\right] t_{2} \leq$ $S_{2}$,

$$
S_{1}=\operatorname{Min}\left[-\left(w-T+t_{1}\right)+\left(\frac{1+\alpha \beta}{\alpha \beta}\right)\left(S_{2}+t_{2}\right), \alpha \beta(w-T)-t_{1}\right] .
$$

if (43) does not hold and if $\left(\frac{2 \alpha \beta^{2}}{1+\beta+2 \alpha \beta+\alpha \beta^{2}}\right) w-\left[\frac{\alpha \beta(1+\beta)}{1+\beta+2 \alpha \beta+\alpha \beta^{2}}\right]\left(T-t_{1}\right)-$ $\left[\frac{(1+\beta)(1+\alpha \beta)}{1+\beta+2 \alpha \beta+\alpha \beta^{2}}\right] t_{2} \leq S_{2} \leq\left[\frac{2 \alpha \beta^{2}}{(1+\alpha \beta)(1+\beta)}\right] w-\left[\frac{\alpha \beta^{2}}{(1+\alpha \beta)(1+\beta)}\right]\left(T-t_{1}\right)-t_{2}$,

$$
S_{1}=-\left(w-T+t_{1}\right)+\left(\frac{1+\alpha \beta}{\alpha \beta}\right)\left(S_{2}+t_{2}\right),
$$

if (43) does not hold and if $\left[\frac{2 \alpha \beta^{2}}{(1+\alpha \beta)(1+\beta)}\right] w-\left[\frac{\alpha \beta^{2}}{(1+\alpha \beta)(1+\beta)}\right]\left(T-t_{1}\right)-t_{2} \leq S_{2}$, then $S_{1}$ is (42).

When $t_{1}=t_{2}=T / 2$, (42) becomes (11). When $t_{1}=0$ and $t_{2}=T,(42)$ becomes (17), and (42) for recipient 2 becomes (20).

\section{Appendix 3: Proof of Proposition 1}

The value of (14) minus the value of (15) is

$$
(1+\beta) \ln \left[\frac{3(1+\beta)}{2+\beta}\right]+\beta \ln \left(\frac{\alpha \beta}{1+2 \alpha \beta}\right) .
$$


If (48) is positive, in the Nash equilibrium each recipient saves little, as in (12). When $\beta=0$ and $\alpha=1 / 2$, the value of (48) is positive. Differentiating (48) with respect to $\alpha$ yields

$$
\frac{\beta}{\alpha(1+2 \alpha \beta)} \text {. }
$$

This expression is positive, and thus large $\alpha$ generates the Nash equilibrium in which each recipient saves little. Differentiating (48) with respect to $\beta$ yields

$$
\frac{3+\beta+2 \alpha \beta}{(2+\beta)(1+2 \alpha \beta)}+\ln \left[\frac{3(1+\beta)}{2+\beta}\right]\left(\frac{\alpha \beta}{1+2 \alpha \beta}\right) .
$$

This expression is negative when $\beta$ is small. Hence, the smaller is $\beta$, the wider is the range of parameters for which the Nash equilibrium has each recipient save little.

\section{Appendix 4: Proof of Proposition 2}

We show that if $t_{1}=t_{2}=\bar{d}(T=2 \bar{d})$ and if recipient 2 saves $\frac{\beta w-t_{1}}{1+\beta}$, as in (34), recipient 1 will save the same amount.

From Appendix 2.2, if recipient 2 saves $\frac{\beta w-\frac{1}{2} T}{1+\beta}$ and if (43) holds, the optimal $S_{1}$ limited to the interval of $S_{1} \leq \alpha \beta(w-T)-t_{1}$ is $S_{1}=\alpha \beta(w-T)-t_{1}$. In other words, in this interval recipient 1's utility increases with $S_{1}$. Hence, he gains by choosing $S_{1}$ in the interval of (32). From Appendix 2.1, recipient 1 will choose (34). is

It therefore suffices to show that (43) holds when $t_{1}=t_{2}=\bar{d}$. From (13), $\bar{d}$

$$
\bar{d}=\left[\frac{1-\beta+\alpha \beta^{2}+2 \alpha \beta}{(1+2 \alpha \beta)(2+\beta)}\right] w .
$$

Using $t_{1}=t_{2}=\bar{d}, T=2 \bar{d}$, and the equation above, $\frac{(\beta-1) w+T-t_{1}}{1+\beta}-\left[\alpha \beta(w-T)-t_{1}\right]$ becomes :

$$
\begin{aligned}
& {\left[\frac{\beta-1-\alpha \beta-\alpha \beta^{2}}{1+\beta}\right] w+\left[\frac{\beta+2+2 \alpha \beta+2 \alpha \beta^{2}}{1+\beta}\right] \bar{d} } \\
= & {\left[\frac{\beta-1-\alpha \beta-\alpha \beta^{2}}{1+\beta}\right] w+\left[\frac{\beta+2+2 \alpha \beta+2 \alpha \beta^{2}}{1+\beta}\right]\left[\frac{1-\beta+\alpha \beta^{2}+2 \alpha \beta}{(1+2 \alpha \beta)(2+\beta)}\right] w } \\
= & {\left[\frac{3 \alpha \beta^{2}}{(1+\beta)(2+\beta)(1+2 \alpha \beta)}\right] w>0 }
\end{aligned}
$$

Hence, (43) holds. 


\section{References}

[1] Becker, Gary S. (1974) "A theory of social interactions." Journal of Political Economy, 82(6): 1063-1094.

[2] Bergstrom, Theodore C. (1989) "A fresh look at the rotten kid theorem-and other household mysteries." Journal of Political Economy, 97(5): 1138-1159.

[3] Bernheim, B. Douglas, Andrei Shleifer, and Lawrence H. Summers (1985) "The strategic bequest motive." Journal of Political Economy, 93(6): 10451076.

[4] Bruce, Neil, and Michael Waldman (1990) "The rotten-kid theorem meets the Samaritan's dilemma." Quarterly Journal of Economics, 105(1): 155-165.

[5] Buchanan, James (1977) "The Samaritan's dilemma." In: Phelps, E.S. (Ed.), Altruism, Morality and Economic Theory, Russell Sage Foundation, New York.

[6] Coate, Stephen (1995) "Altruism, the Samaritan's dilemma, and government transfer policy." American Economic Review, 85(1): 46-57.

[7] Cox, Donald, Bruce E. Hansen, and Emmanuel Jimenez (2004) "How responsive are private transfers to income? Evidence from a laissez-faire economy." Journal of Public Economics, 88(10): 2193-2219.

[8] Diamond, Peter A. (1977) "A framework for social security analysis." Journal of Public Economics, 8(3): 275-298.

[9] Hochguertel, Stefan, and Henry Ohlsson (2009) "Compensatory inter vivos gifts." Journal of Applied Econometrics, 24(6): 993-1023.

[10] Hochman, Harold M., and James D. Rodgers (1969) "Pareto optimal redistribution." American Economic Review, 59(4): 542-557.

[11] Homburg, Stefan (2000) "Compulsory savings in the welfare state." Journal of Public Economics, 77(2): 233-239.

[12] McGarry, Kathleen and Robert F. Schoeni (1995) "Transfer behavior: Measurement and the redistribution of resources within the family." Journal of Human Resources, 30: S184-226.

[13] Roberts, Russell D. (1984) "A positive model of private charity and governmental transfers." Journal of Political Economy, 92(1): 136-148.

[14] Veall, Michael R. (1986) "Public pensions as optimal social contracts." Journal of Public Economics, 31(2): 237-251.

[15] Warr, Peter G. (1982) "Pareto optimal redistribution and private charity." Journal of Public Economics, 19(1): 131-138. 


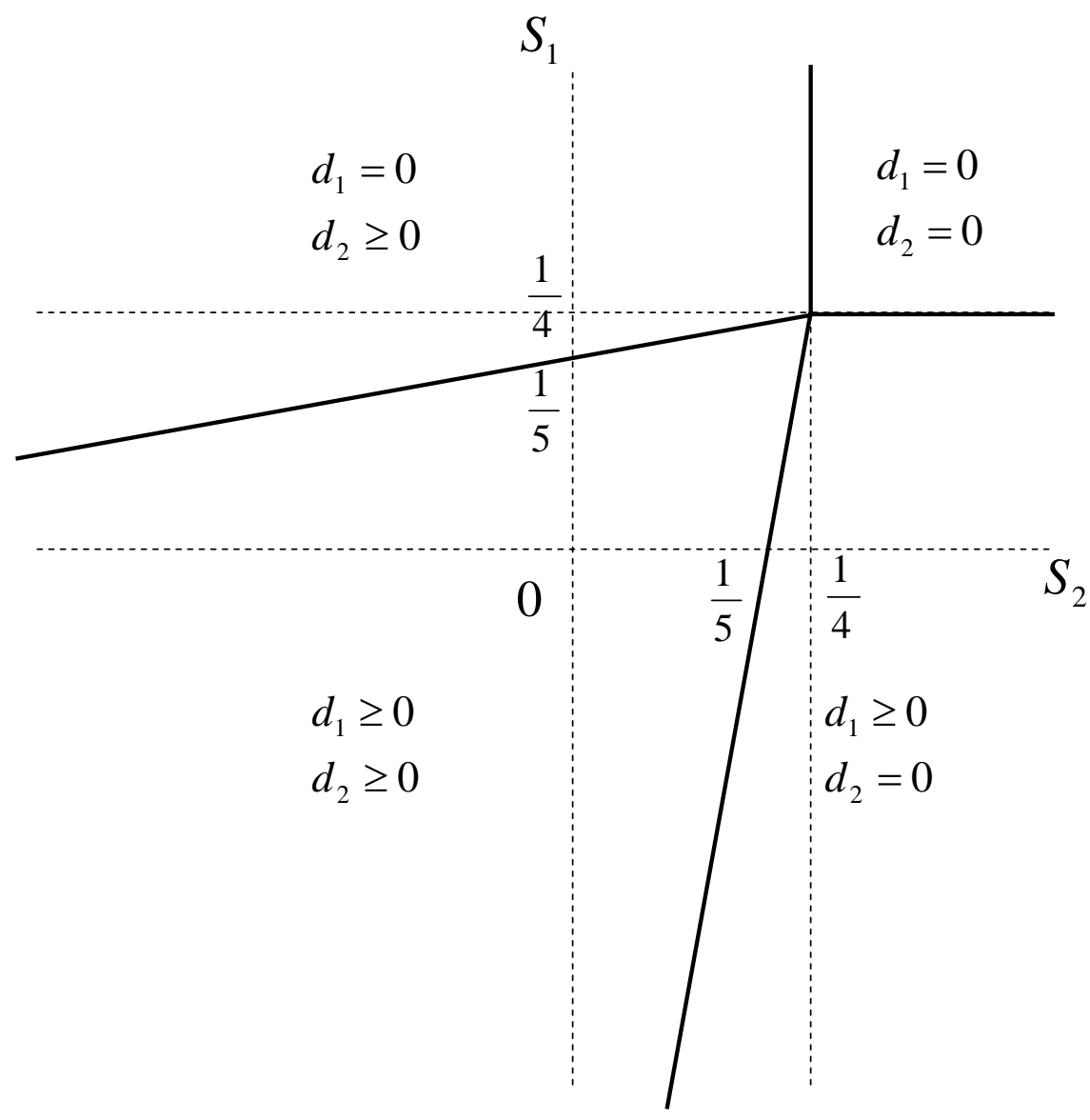

Figure 1

Private transfer $\left(d_{1}\right.$ and $\left.d_{2}\right)$ as a function of recipients' savings $\left(S_{1}\right.$ and $\left.S_{2}\right)$ $\alpha=0.5, \beta=0.5, w=1$ and $T=0$. 


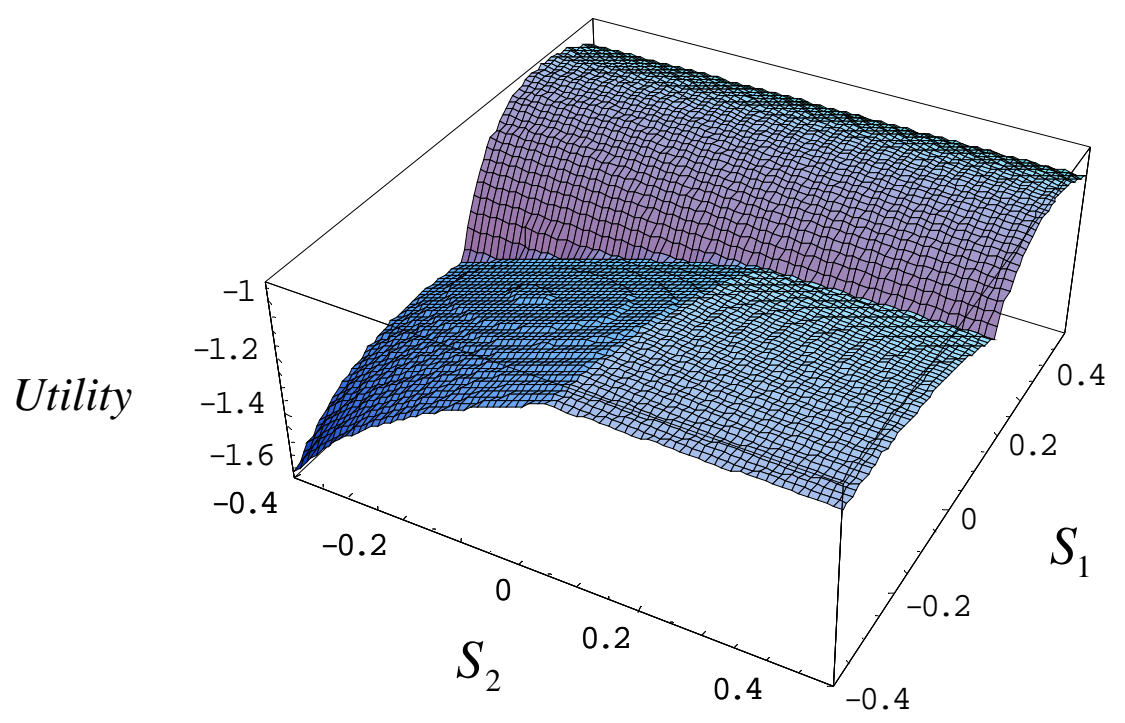

Figure 2(i)

Recipient 1's utility as a function of savings $\left(S_{1}\right.$ and $\left.S_{2}\right)$ when government makes no transfer.

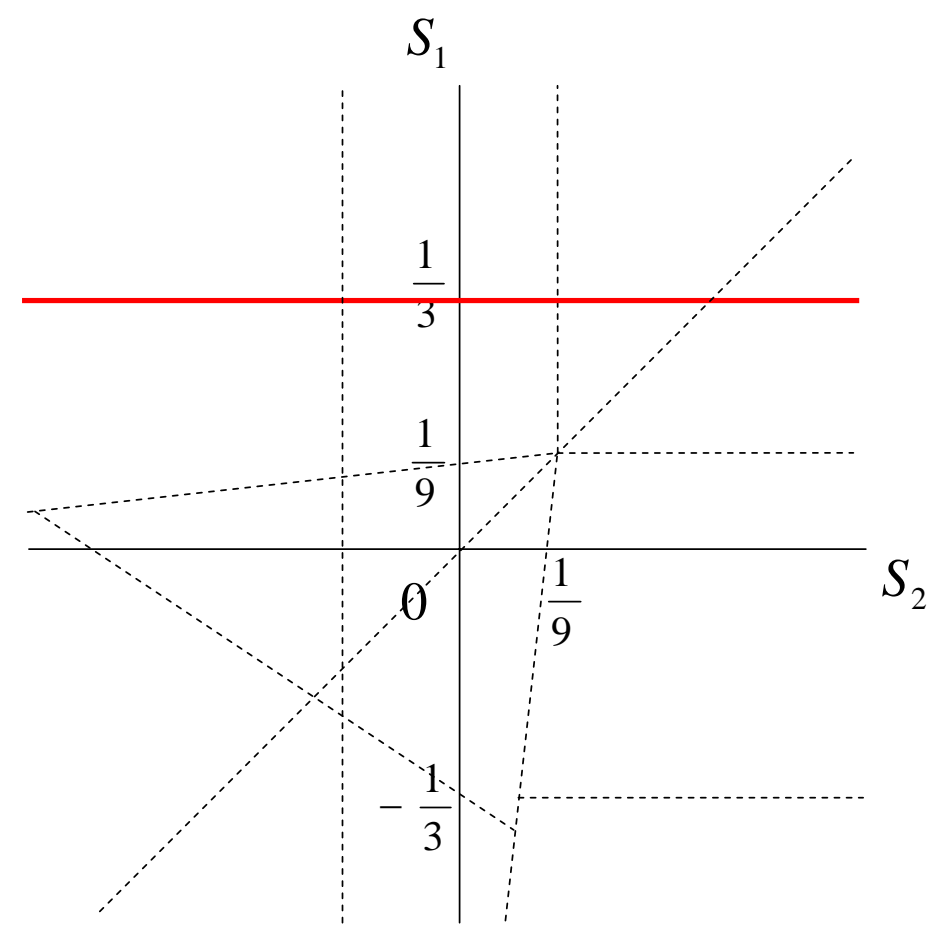

Figure 2(ii)

Recipient 1's savings $\left(\mathrm{S}_{1}\right)$ as a function of the other's savings $\left(\mathrm{S}_{2}\right)$ when government makes no transfer $\alpha=0.25, \beta=0.5, w=1$ and $T=0$. 


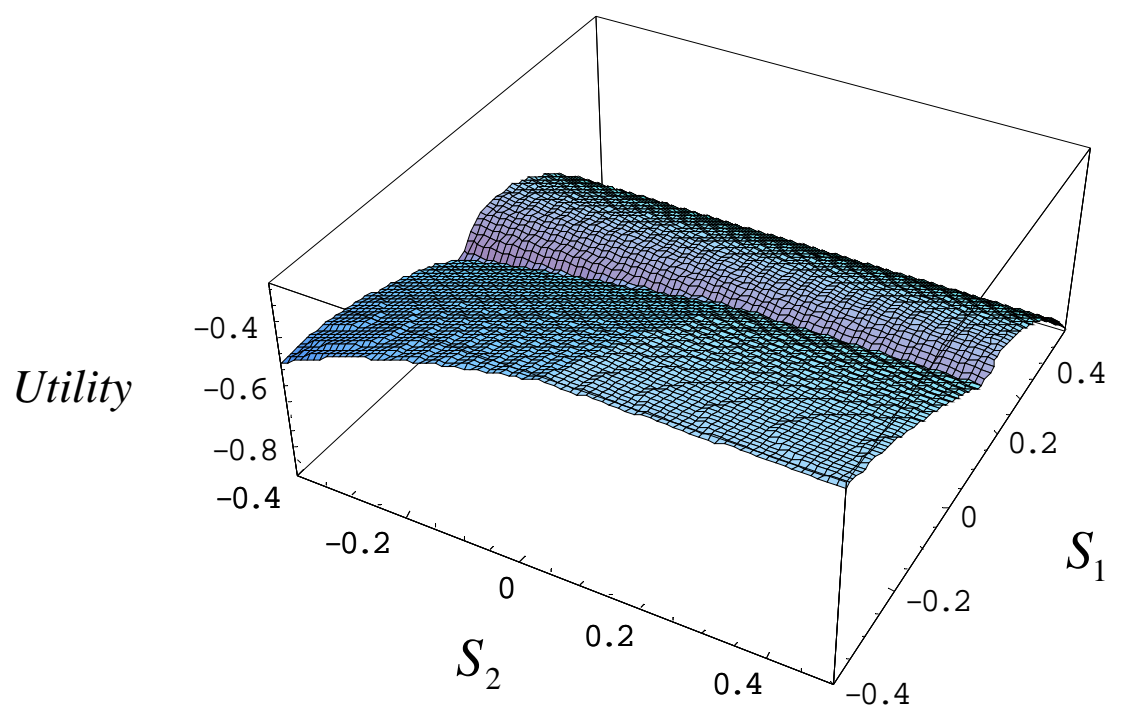

Figure 3(i)

Recipient 1's utility as a function of savings $\left(S_{1}\right.$ and $\left.S_{2}\right)$ when government makes no transfer.

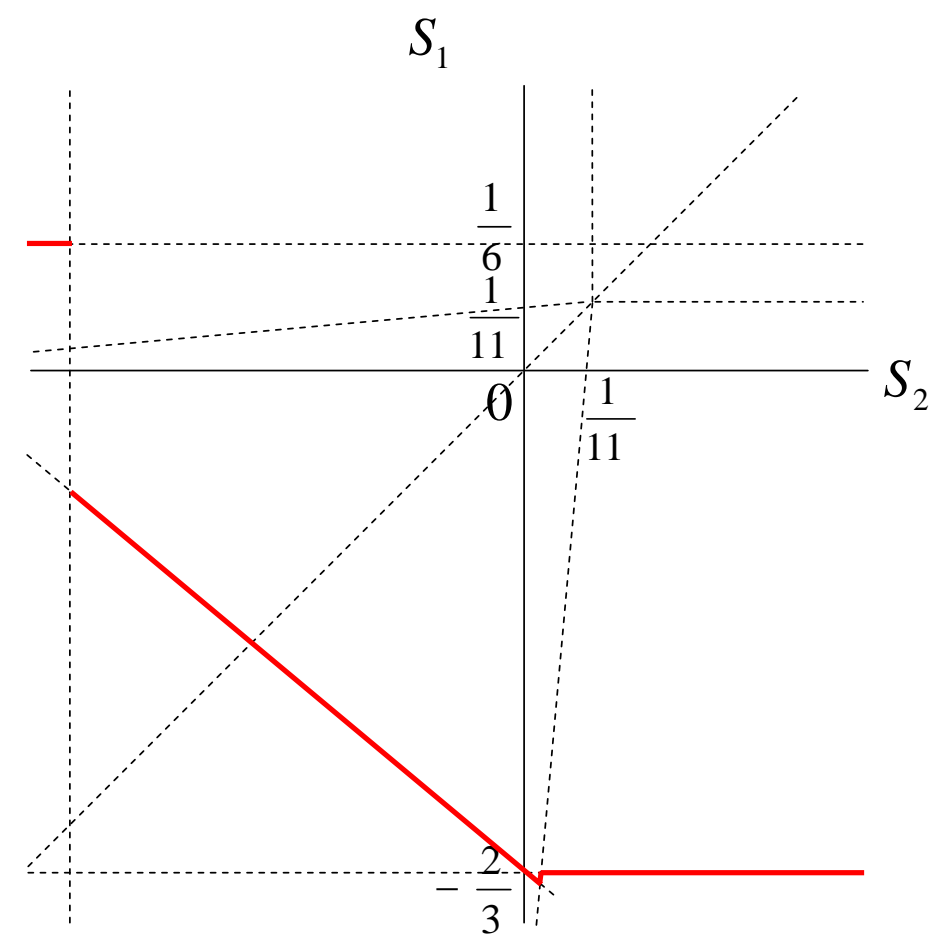

Figure 3(ii)

Recipient 1's savings $\left(\mathrm{S}_{1}\right)$ as a function of the other's savings $\left(\mathrm{S}_{2}\right)$ when government makes no transfer $\alpha=0.5, \beta=0.2, w=1$ and $T=0$. 


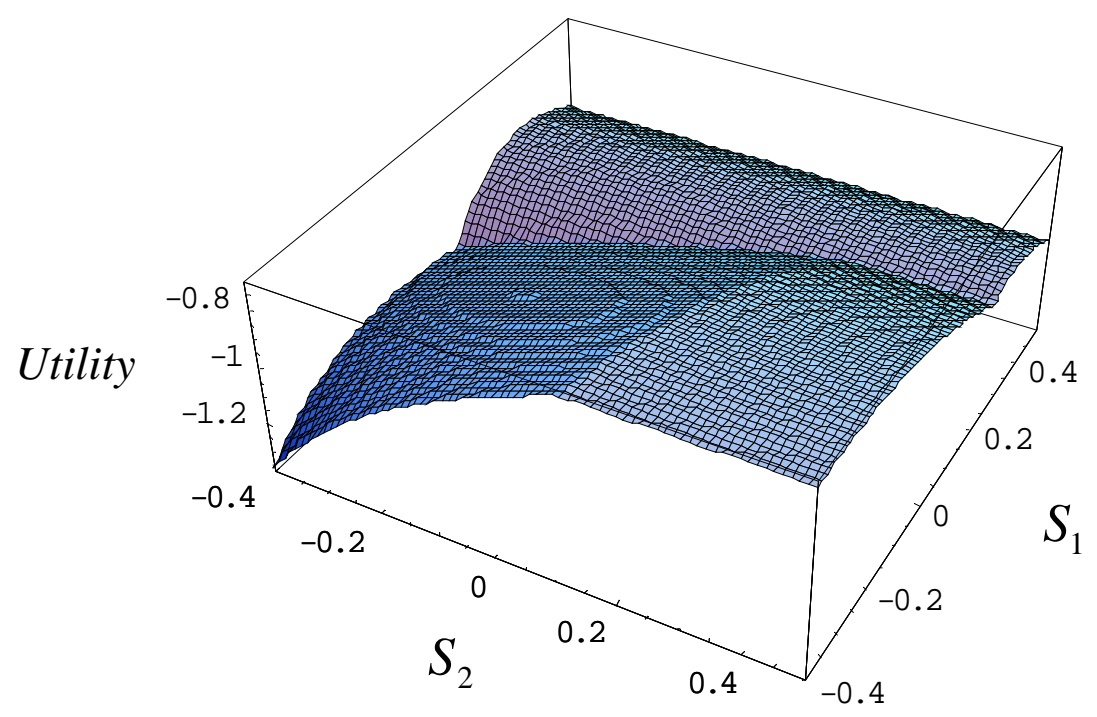

Figure 4(i)

Recipient 1's utility as a function of savings $\left(S_{1}\right.$ and $\left.S_{2}\right)$ when government makes no transfer.

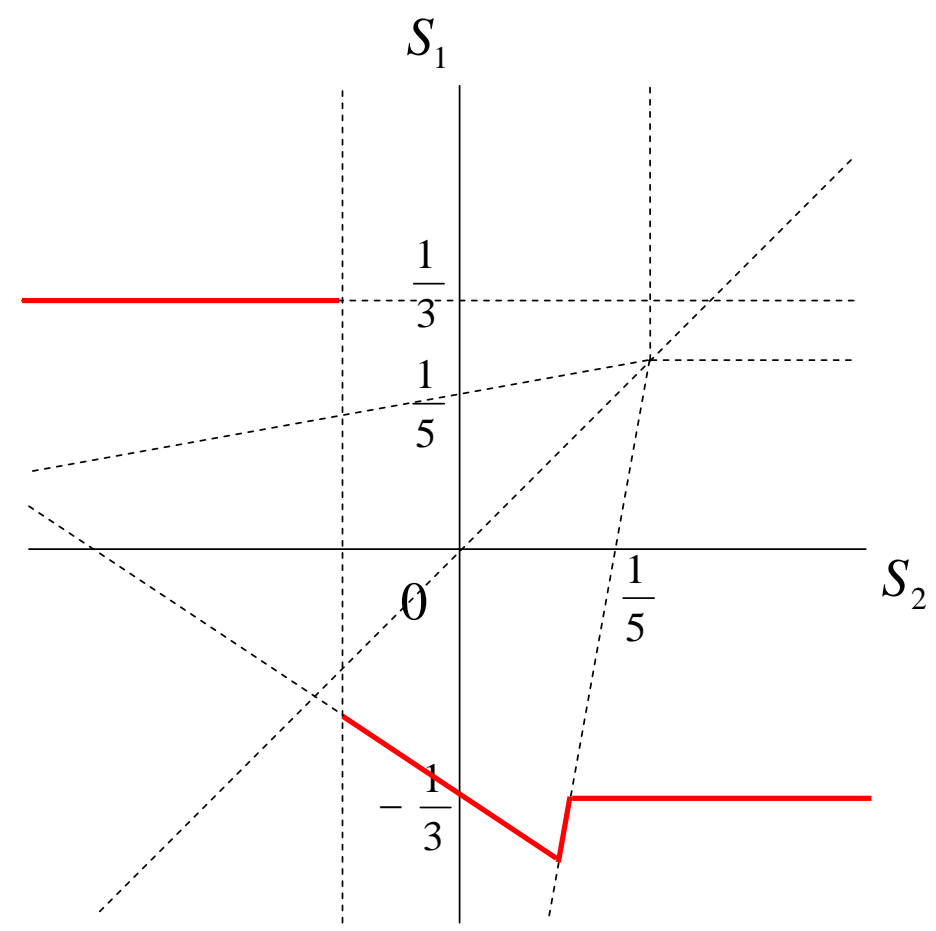

Figure 4(ii)

Recipient 1's savings $\left(\mathrm{S}_{1}\right)$ as a function of the other's savings $\left(\mathrm{S}_{2}\right)$ when government makes no transfer $\alpha=0.5, \beta=0.5, w=1$ and $T=0$. 


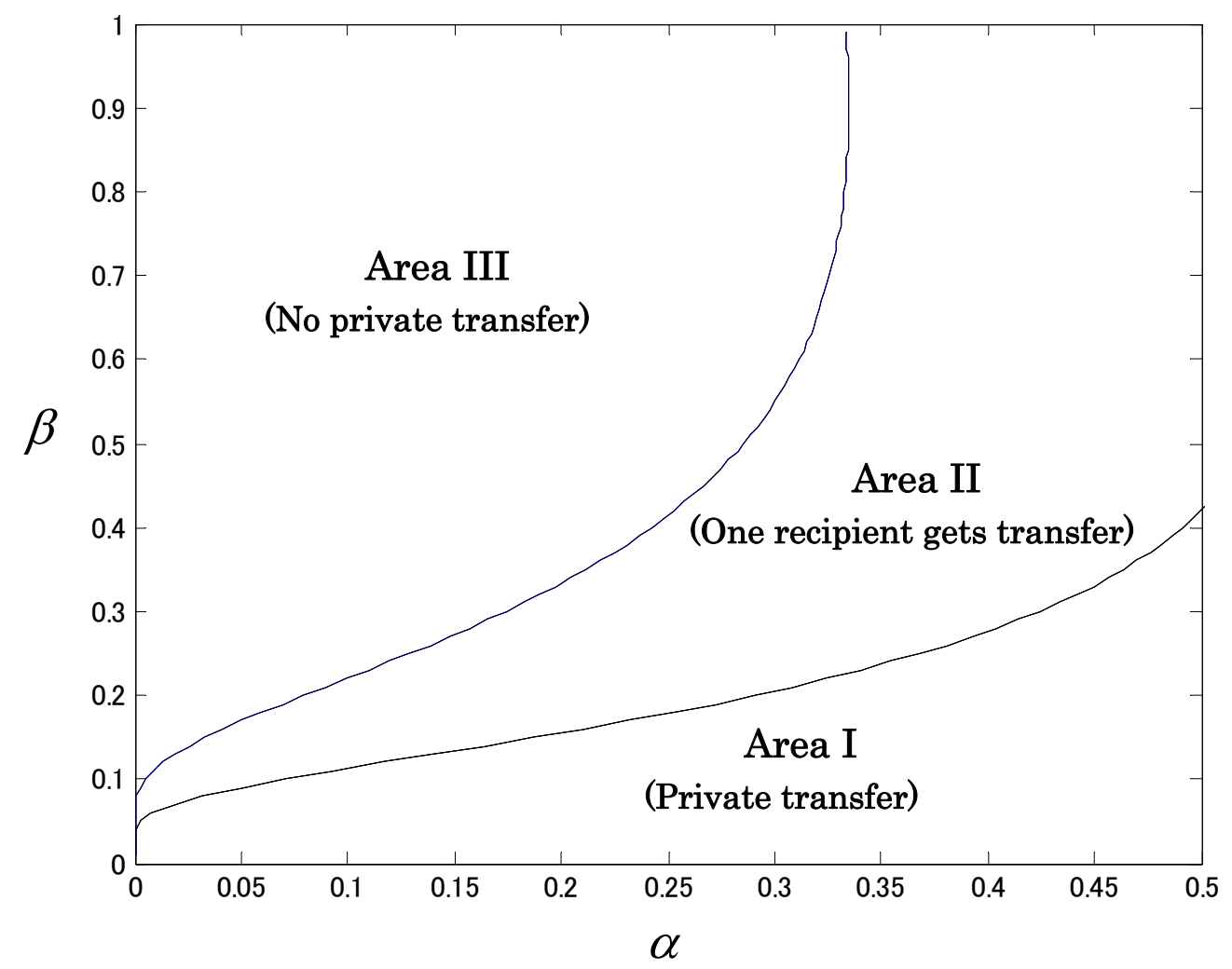

Figure 5

Types of equilibria depend on donor's altruism $(\alpha)$ and recipient's discount factor $(\beta)$ 


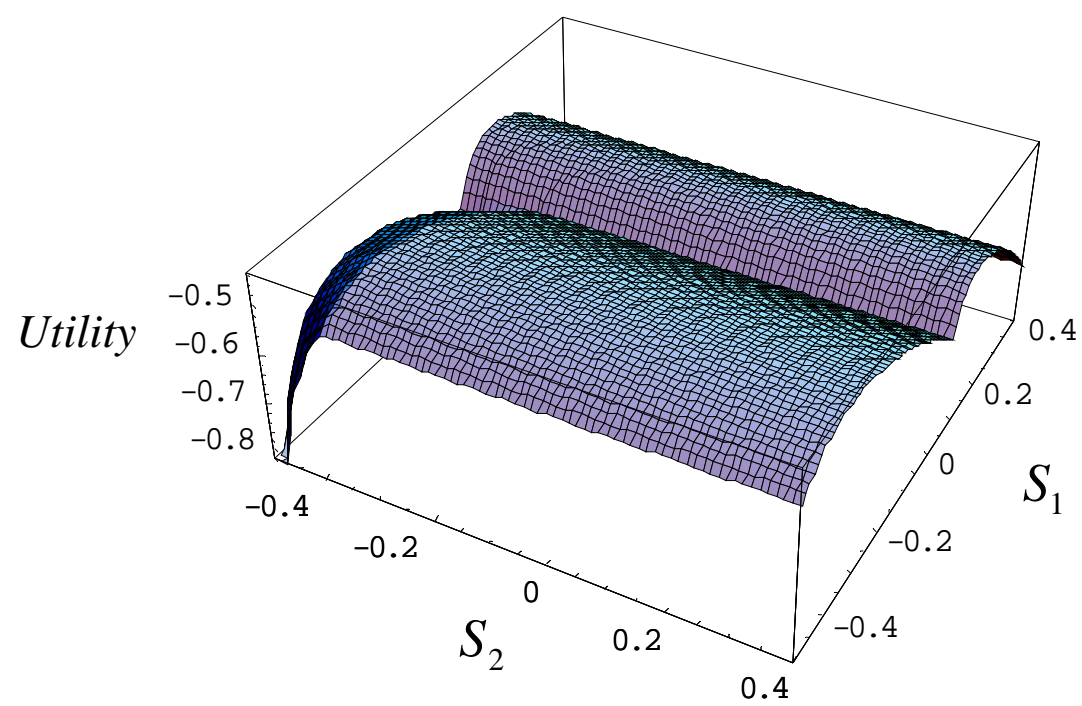

Figure 6(i)

Recipient 1's utility as a function of savings ( $S_{1}$ and $S_{2}$ ) when government makes a transfer to only recipient 2 .

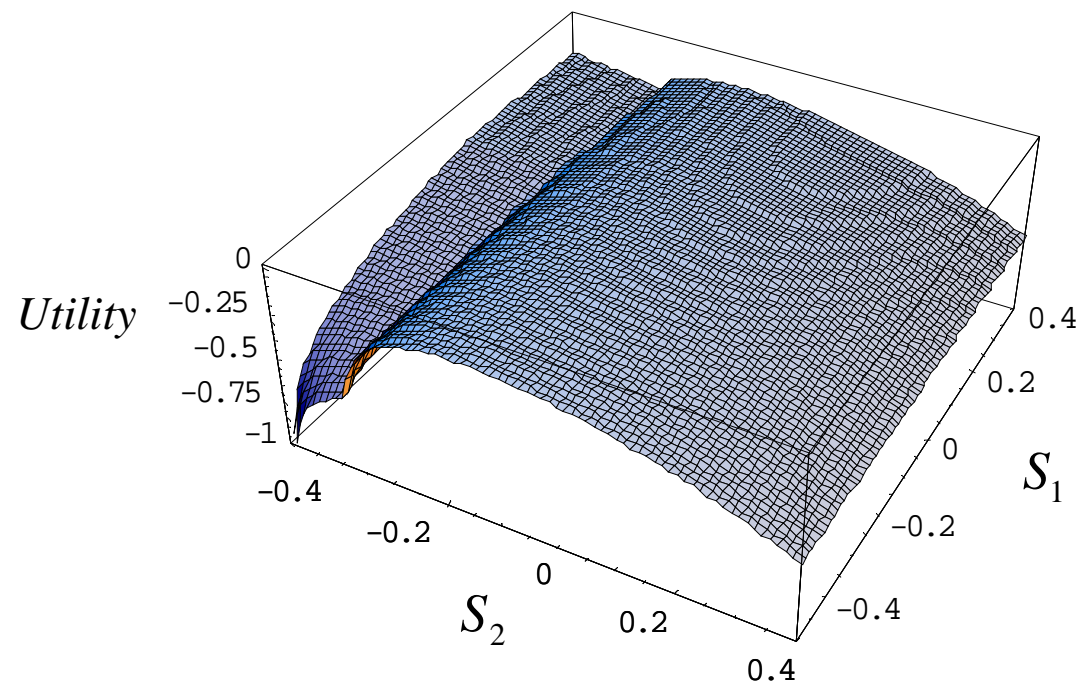

Figure 6(ii)

Recipient 2's utility as a function of savings ( $\mathrm{S}_{1}$ and $\left.\mathrm{S}_{2}\right)$ when government makes a transfer to only recipient 2 . 


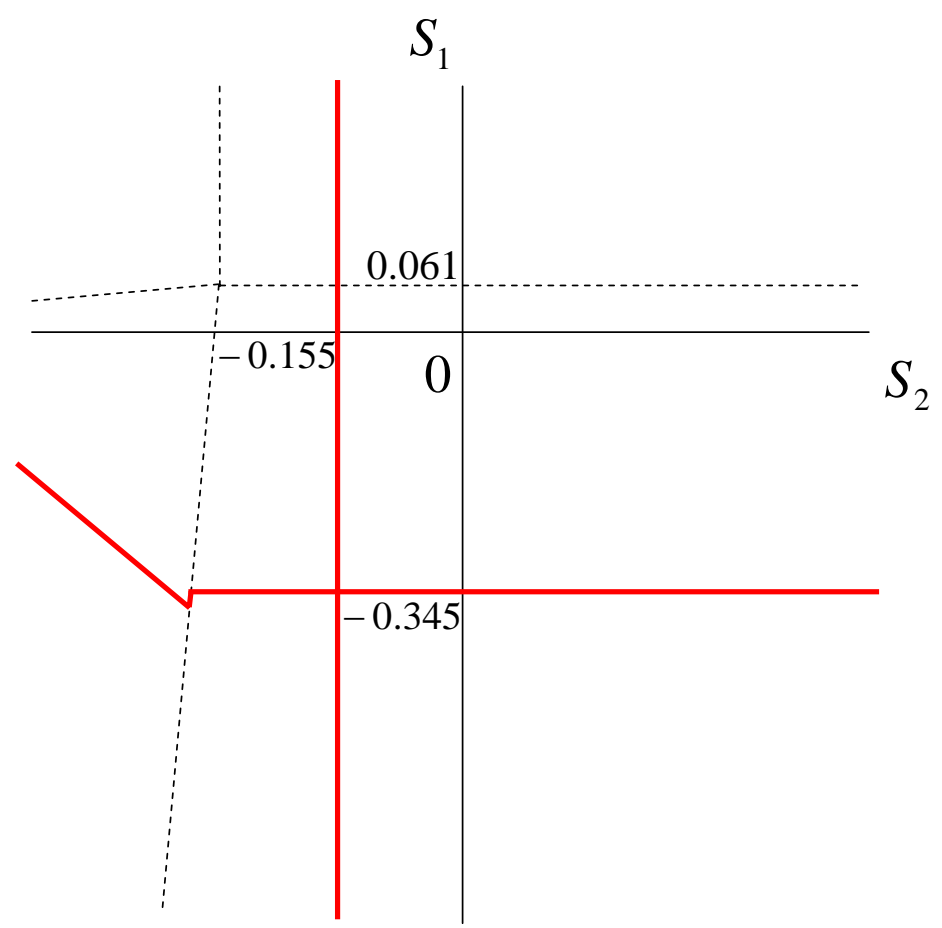

Figure 6(iii)

Recipient's savings as a function of the other's savings when government makes transfer to only recipient 2 $\alpha=0.5, \beta=0.2, w=1$ and $T=0.386$. 